\title{
Valve spool and valve sleeve annular gap value simulation analysis and optimization in hydraulic rotary self servo valve
}

\author{
Xiaolei Liu ${ }^{\mathrm{a}}$, Lin Jiang ${ }^{b^{*}}$, Qi Hu${ }^{\mathrm{c}}$, Ruolin $\mathrm{Wu}^{\mathrm{d}}$, Yanhui Xiang ${ }^{\mathrm{e}}$ \\ Wuhan University of Science and Technology Wuhan 430081, China \\ a13545249159@163.com, b’j|xyhjl@163.com, \\ c512196278@qq.com, ${ }^{\mathrm{d}} 515342747 @ q q . c o m,{ }^{\mathrm{e}} 112497485 @ q q . c o m$
}

Keywords: hydraulic rotary self servo valve; oil film; energy loss; optimum annular gap

Abstract: The internal flow field model of valve spool and valve sleeve annular gap was established. The model was called oil film. The fluid motion state space was laminar flow by calculating of Reynolds number. The formulas about resistance torque and leakage of the valve spool and the valve sleeve annular gap were obtained by calculating. The formula of the energy loss was also obtained by calculating. The optimum annular gap which could make the energy loss to be minimum was obtained from the energy loss formula. In the conditions that valve spool and valve sleeve annular gap had different value, some fluid simulations were done by using FLUENT software. The simulation results showed that the two optimum annular gaps making the energy loss to be minimum was consistent with each other. The one optimum annular gap was obtained by calculating, the other optimum annular gap was obtained by fluid simulation. This provided a basis for optimization of the valve spool and valve sleeve gap value.

\section{INTRODUCTION}

In high precision servo control system, leakage serious affected the control accuracy and frequency response characteristics of the hydraulic system, decreased the overall efficiency of the system. And the gap seal had the advantages of simple structure, long service life, easy maintenance, high efficient [1]. The throttle effect appeared when the sealed fluid passed through the small annular gap, so as to prevent leakage. Compared with the contact type seal, the sealing surface profile peak did not contact, sealing surface was completely separated from the fluid film. The friction condition was for hydrodynamic lubrication.

Gap seal was one of the non contact seal methods. Gap seal which was used in rotating and reciprocating machinery was the sealing technology based on the theory of fluid lubrication.

Research priority of the gap seal was to reduce leakage, improve the operation stability and prolong the service life. Gap seal could greatly improve the motion performance of components. The deficiency of gap seal was long-term work would make the wear increase, reduce the sealing performance leading to increased leakage. The gap width was the decisive factor to control leakage, therefore the appropriate gap width was critical important.

In current high-end products in the rotary servo valve, non-contact seal was widely used. The primary problem of these servo valves was to make sure the gap width. From the annular slot axial flow theory we could get that the leakage was proportional to gap triple, so it could be used to reduce the gap to reduce leakage. General the gap was from $0.01 \mathrm{~mm}$ to $0.05 \mathrm{~mm}$. The mating surface must have high machining accuracy to guarantee of the system running. This paper determined the best gap seal which could be obtained when the minimum power loss in the annular gap between the valve spool and valve sleeve by simulation based on the analysis of internal flow field of valve spool and valve sleeve. 


\section{HYDRAULIC ROTARY SELF SERVO VALVE}

Structure of hydraulic rotary self servo valve was schematically shown in figure 1. It mainly comprised a connecting cover, servo motor, valve spool, valve sleeve, valve body, cylinder, the fixed block and vane. A fixed block was installed in the inner wall of the cylinder body. A fixed vane was installed in the outer wall of the valve body. Valve sleeve and valve body were fixed together with a cylindrical pin $[2,3,4]$.

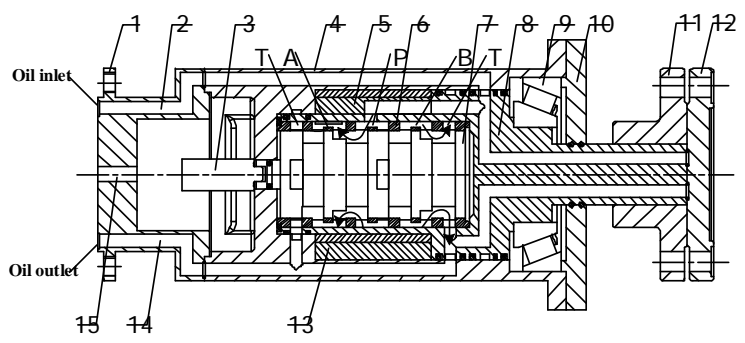

1 connecting cover, 2 low pressure oil passage, 3 servo motor, 4 cylinder, 5 fixed block, 6 valve sleeve, 7 valve spool, 8 valve body, 9 bearing, 10 right cover, 11 flanges, 12 sealed cover, 13 vane,

14 high pressure oil passage, 15 power line channel

Fig 1 Structure of hydraulic rotary self servo valve

\section{ANALYSIS RING GAP OF VALVE SPOOL AND VALVE SLEEVE}

\section{Flow velocity model of valve spool and valve sleeve fluid}

The mainstream velocity was $u^{\prime}$. Induced velocity was $u^{\prime \prime}$. Flow velocity of $u$ was the superposition of $\mathrm{u}^{\prime}$ which was caused by the pressure difference and $\mathrm{u}^{\prime \prime}$ which was caused by the relative surface motion induced velocity.

The mainstream velocity of $u^{\prime}$ and induced velocity of $u^{\prime \prime}$ were perpendicular to each other, just as shown in Figure 2.

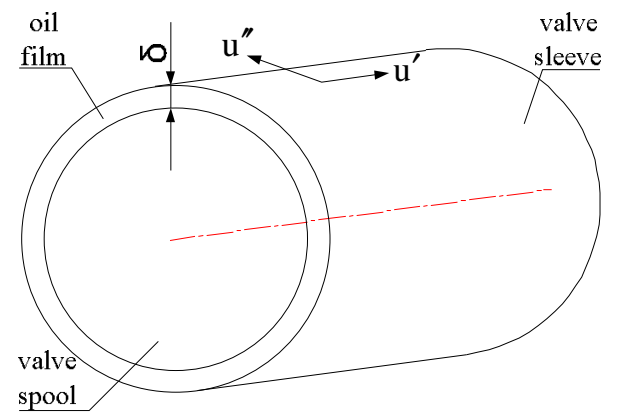

Fig 2 Relative movement velocity analysis chart of valve spool and valve sleeve

\section{Calculation of the gap between the valve spool and the valve sleeve}

The total power losses in the wall gap which was made up of relative movement walls was caused by friction and leakage. The total power losses equation was just as follow [5,6].

$$
\begin{aligned}
& E_{f}=q \Delta p+N_{f} \\
& =2 \frac{\pi d \Delta p^{2} \delta^{3}}{12 \mu l}+\frac{\mu U^{2} \pi l^{\prime} d}{\delta}
\end{aligned}
$$

In equation (1), the $\mathrm{q} \Delta \mathrm{p}$ expressed the leakage power losses, the $\mathrm{Nf}$ expressed the friction power losses, the $\delta$ expressed the gas value between valve spool and valve sleeve.

The total power losses of Ef changed the value with the value change of $\delta$. 
The minimum power losses of Ef was as follows.

$$
\frac{d E_{f}}{d \delta}=\frac{\pi d(\Delta p)^{2} \delta^{2}}{2 \mu l}-\frac{\mu U^{2} \pi d l^{\prime}}{\delta^{2}}=0
$$

From equation (2), we can got the equation of $\delta 0$.

$$
\delta_{0}=\left(\frac{2 \mu^{2} U^{2} l l^{\prime}}{(\Delta p)^{2}}\right)^{\frac{1}{4}}
$$

In the condition that the $\mu$ was $0.027840 \mathrm{~Pa} \cdot \mathrm{s}$, the 1 was $8 \mathrm{~mm}$, the $1 /$ was $40 \mathrm{~mm}$, the w was $90 \mathrm{rad} / \mathrm{s}$, the U was $1.62 \mathrm{~m} / \mathrm{s}$, the $\Delta \mathrm{p}$ was $5 \mathrm{MPa}$, we could get that the $\delta 0$ was $0.0150 \mathrm{~mm}$.

\section{Calculation oil flow Reynolds number of valve spool and valve sleeve}

Reynolds number of valve spool and valve sleeve was as follows [7].

$$
\mathrm{Re}=v \mathrm{dH} / v
$$

In equation (4), $v$ was wall surface relative speed, $v$ was oil's kinematic viscosity. In the condition that the $v$ was $1.62 \mathrm{~m} / \mathrm{s}$, the $v$ was $32 \mathrm{~mm}^{2} / \mathrm{s}$, the $\mathrm{dH}^{\prime}$ was $0.030 \mathrm{~mm}$, we could get that the Re was 1.519 .

The Re value was far less than the lower limit value of the Reynolds number 1100, so this flow model was laminar flow.

\section{Oil flow equation between valve spool and valve sleeve}

Considering the influence of initial period of laminar flow, flow equation should be revised by coefficient $\mathrm{C}$. The flow equation was just as follow.

$$
q=\frac{\mathrm{b} \Delta p \delta^{3}}{12 \mu l c}
$$

In (5), the coefficient $\mathrm{C}$ was $1+\xi \operatorname{Re} \delta /(481)$.

The flow equation of the two parallel cylindrical surface concentric ring slit was just as follow [8].

$$
q_{1}=2 \times \frac{\pi d \Delta p \delta_{0}^{3}}{12 \mu l c}
$$

In the condition that the $\Delta \mathrm{p}$ was $5 \mathrm{MPa}$, the $\mathrm{d}$ was $36 \mathrm{~mm}$, the $\delta 0$ was $0.0150 \mathrm{~mm}$, the $\mu$ was $0.027840 \mathrm{~Pa} \cdot \mathrm{s}$, the 1 was $8 \mathrm{~mm}$, the c was approximate 1 , we could get from (6) that the q1 was $1427.46 \mathrm{~mm}^{3} / \mathrm{s}$.

The theory required driving torque of spool valve

In the dynamic friction surface, the expression of tangential force was just as follow.

$$
F_{f_{1}}=\int \tau_{1} d A=\int-\frac{\Delta p \cdot \delta}{2 l} d A=-\frac{\pi d \Delta p \delta}{2}
$$

In the dynamic friction surface, the expression of axial force was just as follow.

$$
F_{f_{2}}=\int \tau_{2} d A=\int \frac{\mu U}{\delta} d A=\frac{\mu U \pi d l}{\delta}
$$

In the condition that the $\mathrm{d}$ was $36 \mathrm{~mm}$, the 1 was $8 \mathrm{~mm}$, the $1 /$ was $40 \mathrm{~mm}$, the $\delta$ was $0.0150 \mathrm{~mm}$, we could get from (7) that the Ff1 was $-4.241 \mathrm{~N}$, from (8) that the Ff2 was $13.602 \mathrm{~N}$.

So the theoretical driving torque Tf need to overcome the torque generated by axial force. The expression of $\mathrm{Tf}$ was just as follow.

$$
T_{f}=F_{f_{2}} \times r
$$


In the condition that the $\mathrm{r}$ was $18 \mathrm{~mm}$, we can get from (9) that the Tn was $0.2446 \mathrm{Nm}$.

\section{RING GAP FLOW FIELD SIMULATION OF VALVE SPOOL AND VALVE SLEEVE}

\section{The fluid model between circular seam}

The Pro/E 3D graphics model was exported to Gambit to generate 3D fluid model.

The needed 3D model was ring shell. The 3D geometry model of Oil film was as shown in Figure 3. The oil film between valve spool upper surface and valve sleeve lower surface was annular. The shape characteristics should be displayed in the grid map.

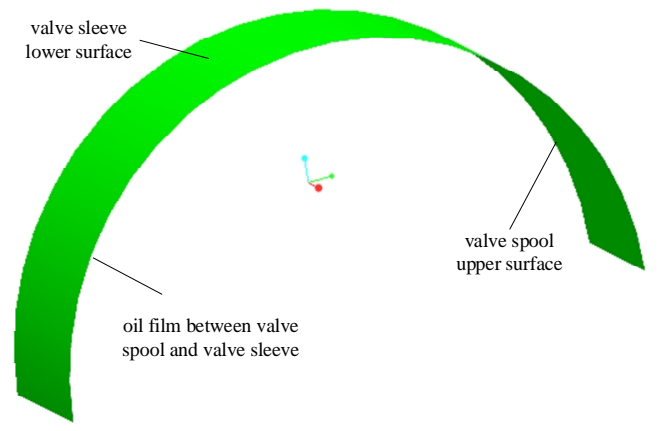

Fig 3 The 3d geometric model of oil film between valve spool and valve sleeve

\section{Grid division using Gambit}

Ring gap flow leakage of valve spool and valve sleeve was affected by model length, model diameter, model gap, et al. The corresponding model was established in accordance with this model to verify the effect of model length, model diameter and model gap. We set up the models by using the gap several different values.

In Figure 4, the model which the difference between valve spool and valve sleeve's radius was $0.015 \mathrm{~mm}$. The gap between valve spool and valve sleeve was small. Firstly, divide the line grid; then divide the surface grid; finally divide the mesh grid. The number of grid was different according to different gap value of $\delta$. The quality of fluent calculation accuracy is largely dependent on the mesh generation[9]. When the $\delta$ was $0.015 \mathrm{~mm}$, the grid was divided into 81000 parts. The pressure inlet and pressure outlet were as shown in Figure 4.

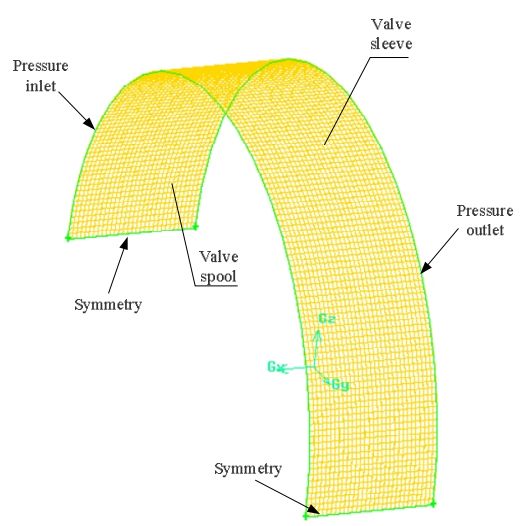

Figure 4 Grid graph of gap oil film

\section{Boundary conditions and calculation condition}

The lower surface of valve sleeve was a stationary surface, the upper surface of valve sleeve was a movement surface. The boundary conditions of import and export were respectively as pressure inlet and pressure outlet. The pressure differences were 5MPa according to the design requirements.

In the calculation process, the following settings were stipulated about flow state of the fluid and valve spool and valve sleeve.

The fluid was not compressible fluid. Flow was laminar flow. Fluid density was $870 \mathrm{~kg} / \mathrm{m}$. The 
antiwear hydraulic oil was selected. The hydraulic oil brand was HM-32, the kinematic viscosity was $32 \mathrm{~mm}^{2} / \mathrm{s}$. The flow in flow field was single-phase flow[10]. The relative rotation angular velocity range between valve spool and valve sleeve were from $3 \mathrm{rad} / \mathrm{s}$ to $90 \mathrm{rad} / \mathrm{s}$.

FLUENT simulation of valve spool and valve sleeve's ring film internal flow

Simulation about valve spool and valve sleeve's different $\delta$. When the $\delta$ was $0.009 \mathrm{~mm}$, the grid was divided into 54000 parts. When the $\delta$ was $0.012 \mathrm{~mm}$, the grid was divided into 67500 parts. When the $\delta$ was $0.015 \mathrm{~mm}$, the grid was divided into 81000 parts. When the $\delta$ was $0.018 \mathrm{~mm}$, the grid was divided into 94500 parts. When the $\delta$ was $0.021 \mathrm{~mm}$, the grid was divided into 108000 parts.

When the $\delta$ was respectively $0.009 \mathrm{~mm}, 0.012 \mathrm{~mm}, 0.015 \mathrm{~mm}, 0.018 \mathrm{~mm}, 0.021 \mathrm{~mm}$, the simulation about the ring film internal flow pressure were done. The simulation results were as shown in Figure 5, Figure 6, figure 7, figure 8, figure 9.

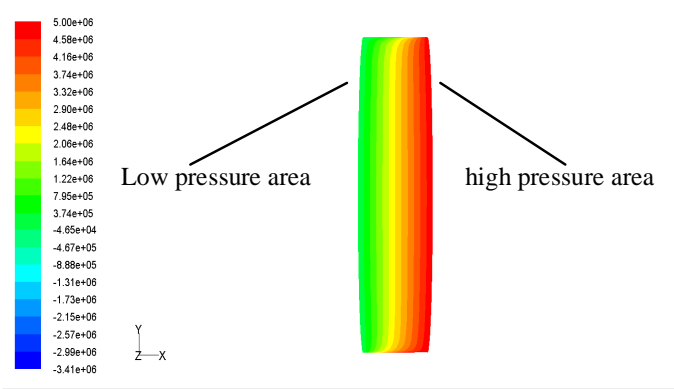

Sep 17,2013
ELUENT 6.3 (30, dp, pons, lam)

Fig 5 Pressure contours when $\delta$ is $0.009 \mathrm{~mm}$

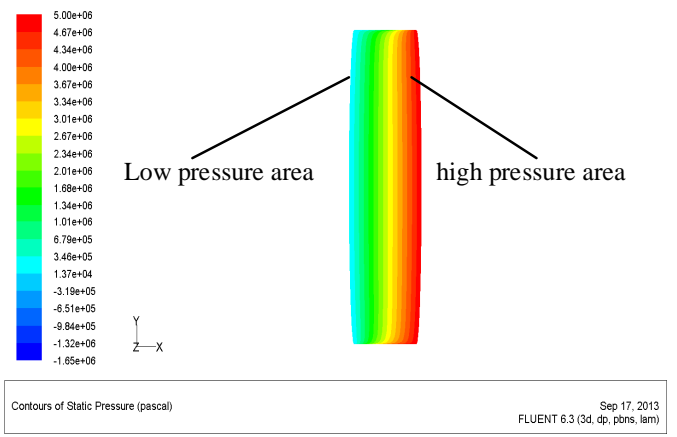

Fig 7 Pressure contours when $\delta$ is $0.015 \mathrm{~mm}$

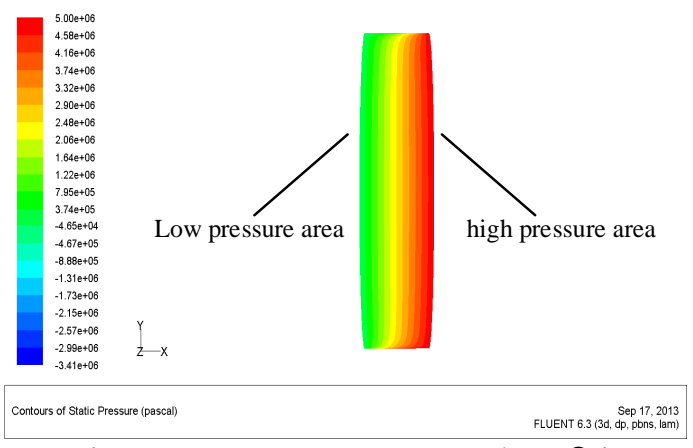

Fig 6 Pressure contours when $\delta$ is $0.012 \mathrm{~mm}$

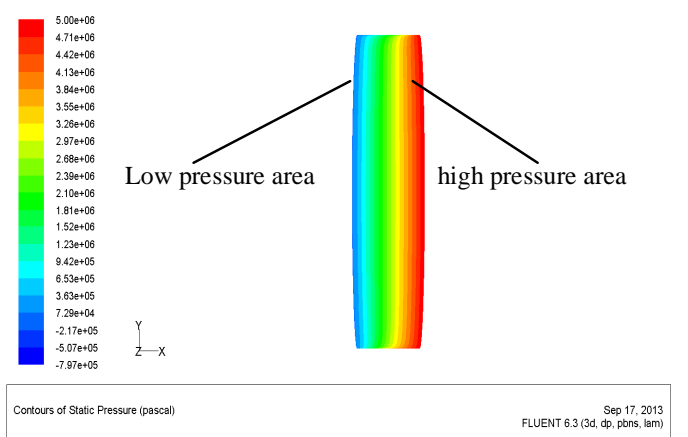

Fig 8 Pressure contours when $\delta$ is $0.018 \mathrm{~mm}$

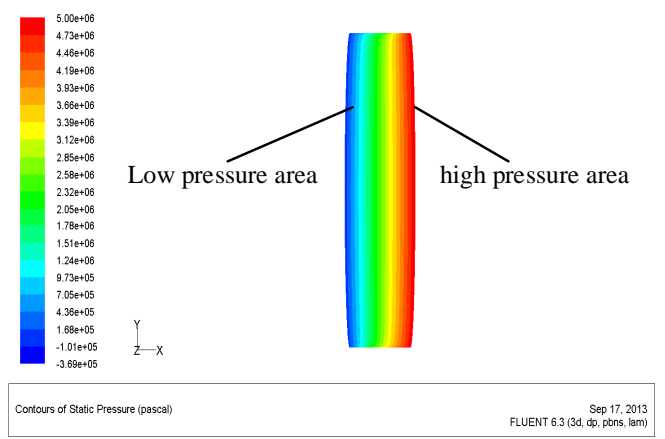

Fig 9 Pressure contours when $\delta$ is $0.021 \mathrm{~mm}$

Analysis and processing of simulation data.The simulation results were as shown in Figure 5, Figure 6, figure 7, figure 8 , figure 9 according to the $\delta$ was respectively $0.009 \mathrm{~mm}, 0.012 \mathrm{~mm}$, $0.015 \mathrm{~mm}, 0.018 \mathrm{~mm}, 0.021 \mathrm{~mm}$. 
The leakage value and resistance torque value were obtained by above simulations. The theory leakage value of annular gap could be obtained from (6). The resistance torque theoretical values of valve spool could be obtained from (7), (8). The theory value and simulation value about leakage value and resistance torque value were as shown in table 1.

Table 1 The theory value and simulation value about leakage value and resistance torque value when $\delta$ have different values

\begin{tabular}{lccccc}
\hline$\delta(\mathrm{mm})$ & $\begin{array}{c}\text { simulation } \\
\text { leakage q } \\
\left(\mathrm{mm}^{3} / \mathrm{s}\right)\end{array}$ & $\begin{array}{c}\text { theoretical } \\
\text { leakage q } \\
\left(\mathrm{mm}^{3} / \mathrm{s}\right)\end{array}$ & $\begin{array}{c}\text { simulation } \\
\text { resistance } \\
\text { torque } \\
(\mathrm{Nm})\end{array}$ & $\begin{array}{c}\text { theoretical } \\
\text { resistance } \\
\text { torque } \\
(\mathrm{Nm})\end{array}$ & $\begin{array}{c}\text { The number } \\
\text { of grid } \mathrm{n}\end{array}$ \\
\hline 0.009 & 307.99 & 308.33 & 0.5098 & 0.4078 & 54000 \\
0.012 & 722.75 & 730.86 & 0.3863 & 0.3058 & 67500 \\
0.015 & 1397.24 & 1427.46 & 0.3130 & 0.2446 & 81000 \\
0.018 & 2381.60 & 2466.66 & 0.2657 & 0.2038 & 94500 \\
0.021 & 3724.13 & 3916.96 & 0.2323 & 0.1747 & 108000 \\
\hline
\end{tabular}

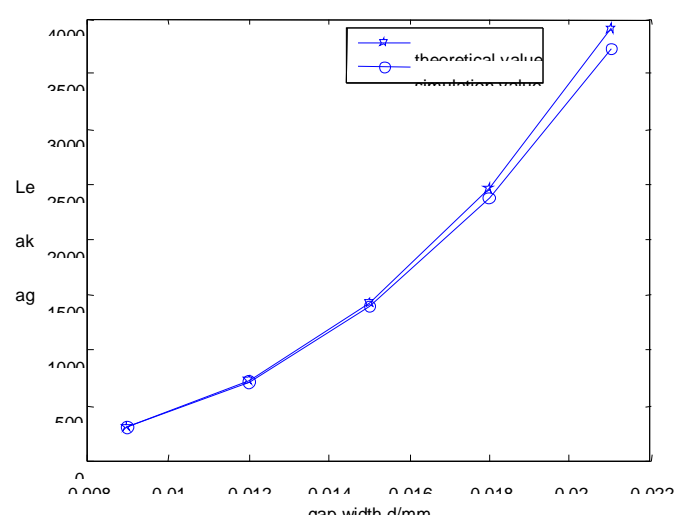

Fig 10 Compared simulation leakage value with theory leakage value in different gap width

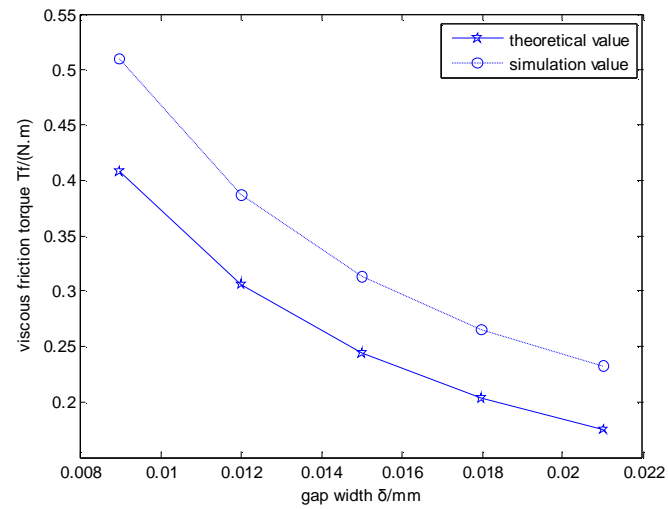

Fig 11 Compared simulation viscous friction value with theory viscous friction value in different gap width

From the simulation diagram and table, we could get the follows conclusions.

Pressure value at the inlet in the graphs is around 5MPa. Pressure value at the outlet in the graphs is around $0 \mathrm{MPa}$. The simulation results are close to the actual situation.

With the increase of $\delta$ values, the drop values of pressure from inlet to outlet changes from gentle to rapid which can be seen from the graph. When the $\delta$ is $0.015 \mathrm{~mm}$, the high pressure value is closest to $5 \mathrm{MPa}$, the low pressure value is closest to $0 \mathrm{MPa}$. The power loss about the friction and leakage is least which can be seen from the previous analysis. Simulation value is close to the actual 
value.

We can see from table 1 that with the increase of $\delta$ values the leakage of spool value and valve sleeve's annular gap is increasing gradually, the resistance torque of valve spool reduces gradually. The resistance moment becomes small at the same time the leakage quantity also becomes small is a pair of contradictions. Only when the $\delta$ is $0.015 \mathrm{~mm}$ can take account of resistance torque smaller and leakage smaller. In this case the energy consumption is minimum.

From the table, we can see that the changing trend of simulation resistance torque in valve spool and theoretical resistance torque in valve spool is roughly the same, and the value of simulation resistance torque in valve spool is close to the value of theoretical resistance torque in valve spool, but the theoretical values are smaller than the simulation values.

This is because in the theoretical calculation, the mainstream velocity $U^{\prime}$ and induced velocity $u$ " are perpendicular to each other, this paper does not consider the influence of induced velocity u", so the theoretical values are small.

Power losses between valve spool and valve sleeve when $\delta$ has different values. To determine the optimal value of the gap, the power losses of different gap values can be obtained from equation (2). The power losses of different gap values are as shown in table 2.

Table 2 Power losses between valve spool and valve sleeve when $\delta$ has different values

\begin{tabular}{cc}
\hline$\delta(\mathrm{mm})$ & power loss $(\mathrm{w})$ \\
\hline 0.009 & 45.42 \\
0.012 & 38.38 \\
0.015 & 35.16 \\
0.018 & 35.82 \\
0.021 & 42.52 \\
\hline
\end{tabular}

We can see from table 2 that the power loss decreased firstly and then increased when the $\delta$ value changed from $0.009 \mathrm{~mm}$ to $0.021 \mathrm{~mm}$. The power loss reached minimum when $\delta$ is $0.015 \mathrm{~mm}$. The $\delta$ is $0.015 \mathrm{~mm}$ which meets the requirement of small amount of leakage and small amount of the resistance torque.

\section{CONCLUSIONS}

This paper discussed the current situation both at home and abroad, then the valve spool and the valve sleeve annular gap model was established. The annular gap model's grid division situation was introduced. The flow field simulation for the valve spool and the valve sleeve's annular gap $\delta$ with different values was done. From the simulation we could get that the leakage and the resistance torque was small when the $\delta$ was $15 \mathrm{~mm}$. In this situation the energy consumption was minimum. The results of theoretical analysis and simulation results verify each other.

\section{CONFLICT OF INTEREST}

This article content has no conflict of interest.

\section{ACKNOWLEDGEMENT}

This work was supported by National Natural Science Foundation(61105086) of China, Self-Planned Task (SKLRS-2010-MS -12) of State Key Laboratory of Robotics and System (HIT), and Hubei Province Natural Science Foundation(2010CDB0 3405).

\section{REFERENCES}

[1] Y. Wenjun, C.Xinyuan, D. Jianghong. "Clamping Force Analysis of Hydraulic Cylinder with 
Piston Sealing”, Chinese Hydraulics \& Pneumatics, No.9, pp.107-109, 2012.(In Chinese)

[2] J. Lin, Z. Hongwei, X. Xianbao, C. Xinyuan, Z. Jie. "Research on Reconfigurable Hydraulic Robot Configuration Based on Genetic Algorithm", International Review on Computers and Software, Vol.6, No.7, pp.1301-1306, 2011.

[3] J. Lin, Z. Jie, W. Wenchao, X. Xianbao, C. Xinyuan, Z. Hui, Z. Liangcai. "Easy Control Hydraulic Rotary Self-Servo Reconfigurable Decoupling Hydraulic Joint". IEEE ICMA 2012, Chengdu, China, 2012, pp.2361-2365.

[4] J. Xiaohong, X. Xianbao, J. Lin, M. Qinfen. "Rollback and Compensation for an Easy Control Hydraulic Servo Joint”. Applied Mechanics and Materials, No.312, pp. 662-666, 2013.

[5] S. Jingchao. Hydraulic fluid mechanics. Beijin: Machinery Industry Press, 1983.(In Chinese)

[6] J. Chaoming. Hydraulic fluid mechanics. Beijin: National Defense Industry Press,1994. (In Chinese)

[7] J. Xiaohong,Li Yuanhui. Fluid mechanics. Beijin: China Electric Power Press, 2011. (In Chinese)

[8] H. Zhidong, J. Jihai. "Research on the Leakage Properties of a Rotating Hydraulic Cylinder with a Deep Circular Groove Oil Film Face Seal". JOURNAL OF HARBIN ENGINEERING UNIVERSITY, Vol.32, No.1, pp.73-78, 2011.

[9] G. Ende. Seal ring and seal gap. At Xiangtan Iron and steel works.

[10] Y. Xiongliang, S. Shili,C. Yu. "The Pressure Behavior of Oil Film in Bearing Subjected to High-frequency Dynamic Load". JOURNAL OF MECHANICAL ENGINEERING, Vol.46, No.17, pp. 93-99, 2010. 